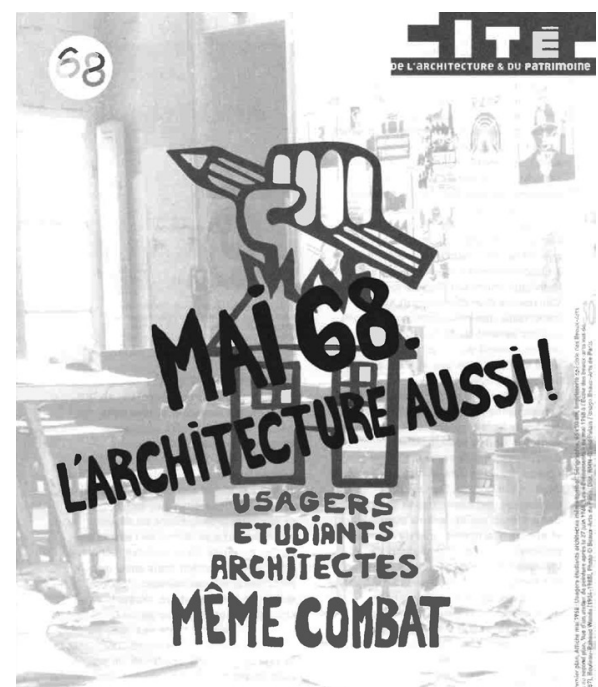

EXPOSITION 16 MAI-17 SEPT. 2018

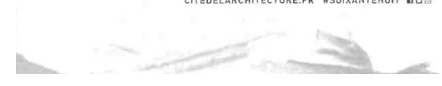

$\wedge$ (IZQ). Póster de la exposición. (DCHA). Imágenes
Arte Moderno de la ciudad de París, marzo 1968

\section{Mai 68}

\section{L'architecture aussi!}

\section{Exposición en la Cité de l'Architecture et du Patrimoine}

Recibido 2018.07.05 :.: Aceptado 2018.07.10

DOI: 10.5821/palimpsesto.18.5679
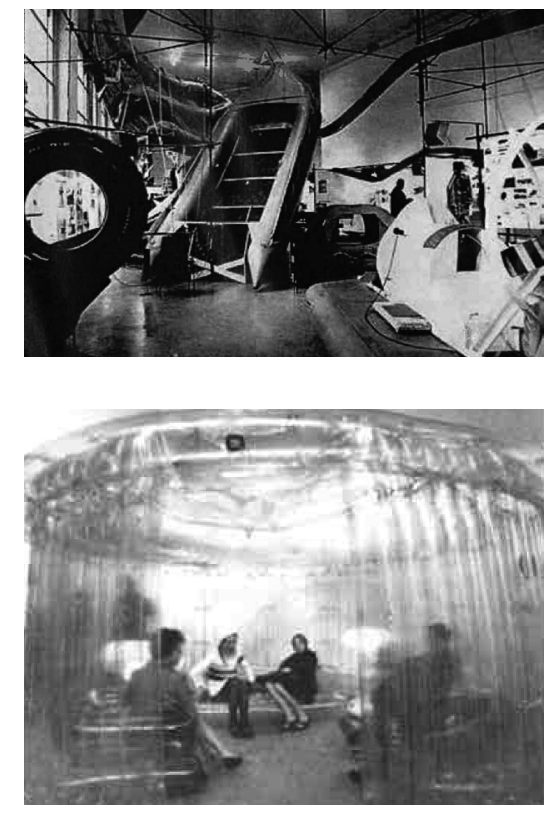

de la exposición Estructuras Hinchables en el Museo de

a Exposición Mai 68. L'architecture aussi! invita a revisitar aquella quincena de años (1962-1977) que asistió a la renovación de la enseñanza acompañando a la de la arquitectura, del urbanismo y de las profesiones vinculadas. El rechazo virulento de la herencia o al menos su evolución, el compromiso de aquellos que hicieron de los años 68 un momento de basculación, la reinvención de las formas y los contenidos pedagógicos que siguieron y finalmente las hipótesis que fueron formuladas por la sociedad y la arquitectura, son las grandes temáticas que permiten analizar esta aspiración a una arquitectura realizada de otra manera.

Mayo 68, el fin de las Bellas Artes, jinventamos! ¿Qué, hacia dónde?, ya veremos.

Las direcciones tomadas a partir de la mitad de los años 60 son múltiples y las encrucijadas, en ocasiones, peligrosas. De las primeras protestas importantes que estallan en la Escuela de Bellas Artes, alrededor de 1966, surge la reivindicación de los estudiantes más aventajados para la Teoría "mayúscula" con -es la clave- un estatus de intelectuales soportado por el aporte decisivo de las humanidades. El compromiso es político -algo consustancial a la izquierda-, pero también intelectual, indisociablemente inclinado hacia la renovación teórica.

Conscientes de un cambio ineluctable, los poderes públicos intentaron acompañar este movimiento elaborando desde 1962 un proyecto de reforma de la enseñanza que mayo 68, con toda la fuerza del evento, interrumpe.

Al curso siguiente, la arquitectura y su enseñanza se reinventan, fuera del cenáculo de las Bellas Artes, a través de las Unidades Pedagógicas Autónomas (UPA). La generación de estudiantes que se forma allí, incluso si su cohesión se fundamenta en el rechazo de un cuadro pedagógico y de prácticas profesionales juzgados obsoletos, crea un ideal y busca transmitir algunas referencias y representaciones compartidas.

"Años de cambio", los años 1968 se extienden hasta el voto, en 1977, de una ley - la ley sobre la arquitectura- que acoge en parte la agitación pionera, orientando en particular a la arquitectura hacia el polo de la calidad, mientras que estaba dominada desde la Reconstrucción por la cantidad. Los arquitectos exploran nuevas hipótesis conceptuales y formales entre experimentaciones técnicas, utopías, la vuelta a la forma, a la ciudad, e incluso a la Historia. La exposición presenta casi 360 documentos originales (dibujos, planos, fotografías, maquetas, publicaciones, filmaciones, entrevistas...).

\section{El rechazo a la herencia}

El fuego incuba bajo la ceniza. El antes del 68 anuncia una profunda ruptura en el seno de los arquitectos. Algunos estudiantes, precisamente no los más mediocres, comienzan a denunciar una estética académica y un arte escolástico donde la idea de lo bello se reduce a un sistema de modelos o donde la práctica del proyecto arquitectónico se reduce a un sistema de reglas. Buscan liberarse de la estética de lo acabado, de lo empaquetado, del control técnico y de la reproducción, pero también de algunas prácticas sociales (folklore, solidaridad viril, novatadas, relaciones entre nuevos y antiguos) que se prolongan fuera de la Escuela por toda una serie de lazos y de jerarquías profesionales. El rechazo se encontrará condensado, en mayo, en la denuncia de la pajarita, símbolo de la vanidad de un arquitecto todavía notable. De una manera más general, los estudiantes-arquitectos se interrogan sobre el sentido mismo de la arquitectura, sobre su dimensión social y societaria. La cuestión de la época no es "qué arquitectura vamos a hacer" sino más bien, "cómo, con quién y para quién la haremos".

\section{¡TODO es política!}

Cruciales, los años 1964-1967 son menos conocidos que el que les sigue, 1968. ¿Mayo de 1968 será el velo de las mutaciones profundas acaecidas anteriormente? De cualquier modo, en 68, TODO es política, jla arquitectura también! Se ostenta la idea de hacer la revolución a través de la arquitectura. El mayo 68 de los arquitectos funciona bajo el tríptico generalización-politización-radicalización. . de las reivindicaciones, de los ideales y de los deseos. Si en Nanterre los sociólogos son vistos como perros de guardia del régimen, los estudiantes de arquitectura ven en los arquitectos en ejercicio "pacificadores sociales" diseccionadores de la ciudad. Rechazan todo aquello que participa del funcionamiento del aparato del poder. La ocupación de la Escuela de Bellas Artes en mayo y junio de 1968 es un momento fundacional, pero la "lucha" se extiende en el tiempo (las movilizaciones siguen hasta 1970) y en el espacio con la aparición de varias plataformas de lucha en el país, particularmente activas en Grenoble, Marsella y Nantes.
La escuela reiventada

El decreto del 6 de diciembre de 1968 iniciado por André Malraux, Ministro de Estado encargado de los Asuntos Culturales, reorganiza la enseñanza de la arquitectura Inspirándose en ella, se inscribe en la continuidad de la ley de orientación sobre la enseñanza superior del 19 de noviembre de 1968 que venía a sentenciar las antiguas facultades en beneficio de las universidades autónomas y pluridisciplinares. Para descentralizar y abrir las estructuras de la enseñanza con el fin de "mejorar la formación científica y técnica de los futuros arquitectos", el decreto certifica el estallido de la sección de Arquitectura de la Escuela nacional superior de Bellas Artes (Ensba) y otorga a sus antiguas antenas regionales una nueva autonomía, al fundar unidades pedagógicas de arquitectura (UPA o UP). Desde enero de 1969, la arquitectura y su enseñanza se reinventan, fuera del cenáculo de las Bellas Artes, bajo el impulso de un cuerpo docente profundamente renovado, a menudo joven y muy comprometido. Las 18 nuevas UP (numeradas de 1 a 8 en Paris) forman pronto otras tantas "escuelas" arquitectónicas, cada una vector de sensibilidades distintas sobre el plano docente, metodológico, teórico, político o estético.

\section{Hipótesis para la arquitectura}

Si la Escuela de Bellas artes fue en efecto uno de los símbolos del mayo parisino, resultaría vano buscar un "estilo" arquitectónico que lo encarne. Mayo 68 coincide con un profundo cuestionamiento del estatus del artista y del arquitecto, y más generalmente de la autonomía y del arquitecto, y más generalmente de la autonom
artística y de las fronteras disciplinares. No existe artística y de las fronteras disciplinares. No existe artista, del arquitecto, del arte en general, en beneficio de expresiones provisionales y espontáneas, efímeras, vividas más que contempladas. El entorno substituye a la obra. La modernidad arquitectónica, formal, austera y repetitiva, se rechaza definitivamente. Al final de los años 68 , los arquitoctos formulan la hipótesis de una vus 68, los arquitectos formulan la hipótesis de una vuelta de una vuelta al color, al ornamento y a la composición. En esta búsqueda, las fricciones entre la enseñanza de la arquitectura y la producción arquitectónica son particularmente fecundas.

\section{Epílogo}

Curioso movimiento de mayo, curioso "movimiento" del giro de los años 60-70 cuya arqueología crítica empezamos justo ahora a abordar, arqueología de hecho de nuestra propia modernidad. Curioso "movimiento" que, después de haber incendiado las referencias clásicas, no supo muy bien -salvo restaurándolas poco después- por cuáles remplazarlas.

Comisariado

Carolina Maniaque, arquitecta e historiadora. Profesora de historia y culturas arquitectónicas en la Esccuela Nacional Superior de Arquitectura de Normandía.

Eléonore Marantz, historiadora. Profesora de conferencias en historia de la arquitectura contemporánea, universidad Paris 1 PanthéonSorbonne.

Jean Louis Violeau, sociólogo. Profesor a la Escuela Nacional Superior de arquitectura de Nantes, investigador del Centro de Investigación de Arquitecturas Urbanitas de Nantes.

Escenografía: Xavier Wrona, arquitecto. Premiado Ajap 2010.

Un agradecimiento especial a FRANCIS RAMBERT, director de departamento de creación arquitectónica de la Cité de l'Architecture et de l'Urbanisme desde 2014 y Presidente de la Escuela Nacional de Arquitectura de París-Val de Seine. Impulsor de la "Plataforma de la creación arqutiectónica" referencia de la arquitectura contemporánea tanto en términos de producción, de prácticas y de tomas de posición, y fundador de la revista trimestral "Archiscopie".

Traducción: Alberto Peñín

ABSTRACT

La exposición ilustra la génesis y las fórmulas de renovación de la enseñanza de la arquitectura en Francia, a lo largo de los años 60 y 70 . En un momento particularmente oportuno, por los debates que suscita y los esfuerzos teóricos que convoca, profesín y más ampliamente la de la arqutectura.

PALABRAS CLAVE: Mayo 68, enseñanza, arquitectura. 